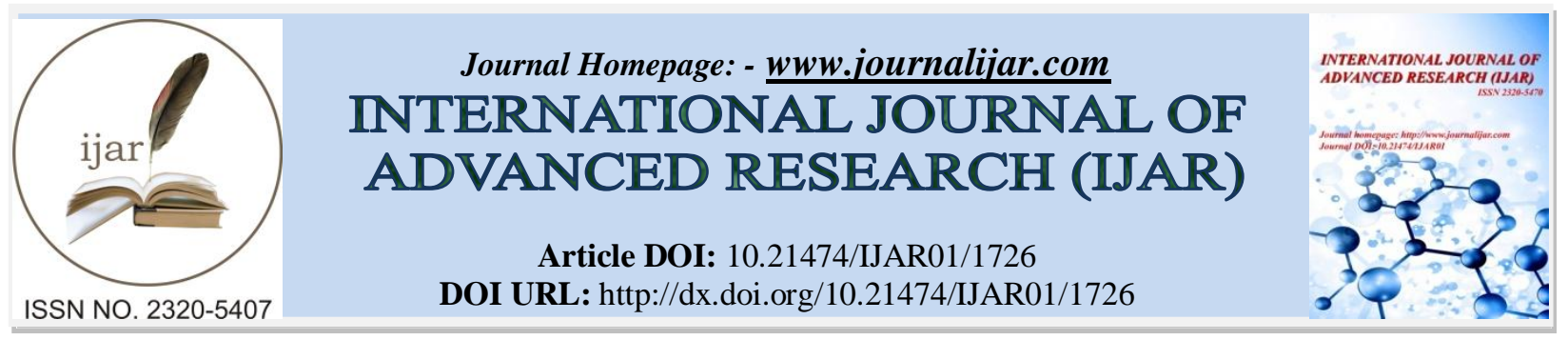

RESEARCH ARTICLE

\title{
AUTOMATION CONTROL ON WATER SUPPLY NETWORKS.
}

\section{Ilir Abdullahu ${ }^{1}$ and Sokol Xhafa ${ }^{2}$.}

1. Departament of Enginnering Construction and Infrastructure,University of Business and Technology,1000 Prishtina,Republic of Kosova.

2. Technical Director RWC "Prishtina" j.s.c., Prishtina, Kosovo.

\section{Manuscript Info}

Manuscript History

Received: 12 July 2016

Final Accepted: 19 August 2016

Published: September 2016

Key words:-

Water Flow, Pressure Control, GPRS

Logger, Pressure Logger, DMA.

\section{Abstract}

Application of new technology and "smart" devices is the most wellknown experience in all type of works for sustainable services, including water supply networks. Measuring from the distance including online monitoring is one of the easiest way to control flow and pressure on these networks, especially on District Metering Areas (DMA). In order to reduce losses in the network, nowadays, online monitoring and controlling is more than a necessity. Water loss reduction is one of the biggest challenges today in the industry of water treatment. Applying these automatic and electronic devices will be presented below with real measures on site and real examples on Regional Water Company Prishtina service area.

Copy Right, IJAR, 2016,. All rights reserved.

\section{Introduction:-}

Water loss reduction is one of the main tasks in RWC Prishtina, also in whole Balkan region, due to high percentage of water loss, as it is presented in international reports and conferences, (International water Benchmark) even though it is fact that Kosovo especially "RWC Prishtina" is in a better level compared to neighboring countries like FYR Macedonia, Albania, Serbia, Montenegro etc.

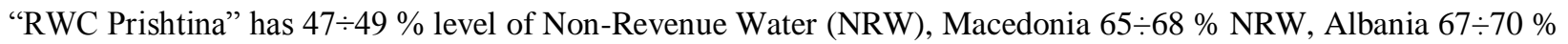
NRW.

Water loss can be controlled in many ways including but not limited to electronic devices, site surveys, automatic and online control, but it also needs a huge activity and work on site depended from different distribution system networks. The purpose of this stage is to identify the area of the network in which leakage is occurring in order to prioritize field surveys. A popular approach is to divide the network into District Meter Areas (DMAs) by closing valves permanently and installing meters equipped with telemetry data loggers in order to allow the Utility to monitor consumption in a continuous way on a particular zone from which an estimate of leakage can be estimated. Another method, known as mobile waste metering, involves valves being shut temporarily and mobile meters, installed in vans and connected via flexible hoses to permanent connections in the network, being used to measure flows. A hybrid system involves permanently installed meters with the boundary valves being closed temporarily to measure a night flow ${ }^{1}$. These days all the utilities in region have an intention to apply IWA rules and regulations, including water balances in order to see and to have a better control in all levels. The ways how to tackle these 
problems on water losses are different on approach but finally all the methods have the same goal, try to achieve the lowest percentage of real water loss. RWC Prishtina is implementing automatic control systems like online monitoring and real measures on site with automation technology. Parallel to the investments on technology, of course, there is a need on training human resources and workers. To monitor and survey such isolated zones (DMA zones), it is mandatory to have a trained staff with right equipment (fully equipped) with all devices. Water loss reduction is closely tied to improved services to the consumers, residents. This paper will be present five pilot DMA-s, and a detailed one in Lipjan town as an online monitoring zone for longer time.

\section{Practices and well known devices for flow and pressure control:-}

The most well-known devices for online monitoring for flow and pressure are gprs pressure loggers, ultrasonic flow meters. As far as leak detections, the collocation method is commonly used.

RWC Prishtina these days has five online monitoring zones, with intention to extend these zones on to 16 more; these days' utility is using online monitoring device with gprs card transmitter as it is shown on the picture below.

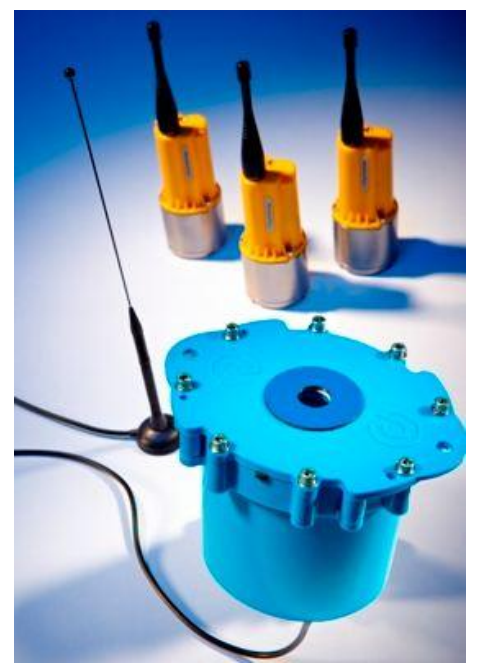

Fig. 1:- GPRS Flow and Pressure Logger.

The devise set up is presented below, of course it needs its own software to set it up, proper bulk water meter with a transmitter plug option, and then on these plugs it is easily accessible to insert the device.
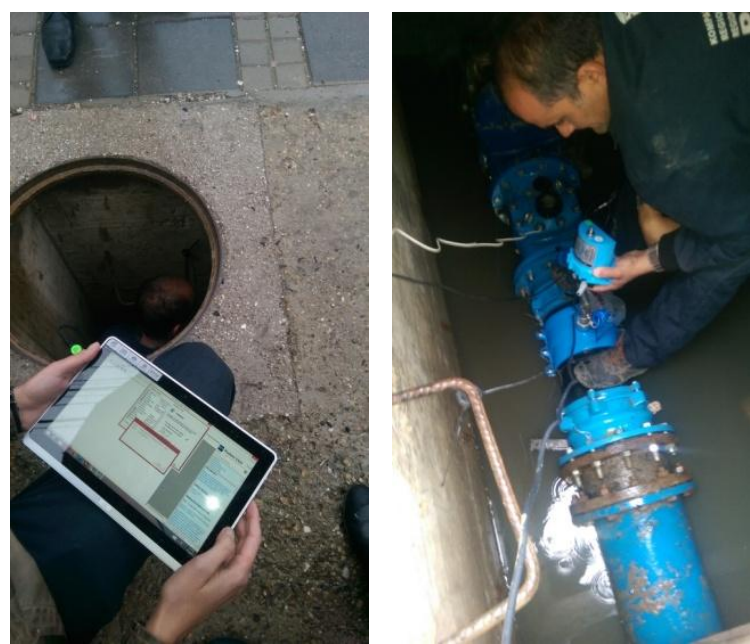

Fig.2:- a)Setting up the device.

Fig. 2:- b) installing into main pipes. 


\section{Results from online monitoring:-}

Zone:
\begin{tabular}{|l|l|l|l|}
\hline -.-Show All-- \\
Site: \\
\hline Fl318, Rr.Enver Maloku sh.f. Ismail Qemajli, Zona I
\end{tabular}
Fleet Summary... Fleet Map.... Alarms...

Logged in as Kur Prishtina. Log out.

Qendra|1 77318, Rr.Enver Maloku sh.f. Ismail Qemajli, Zona I Phone: 37745987136 Site ID: loger 1 From: 29Jun2016 20:00 To: 30Jun2016 20:00 (15 Mins

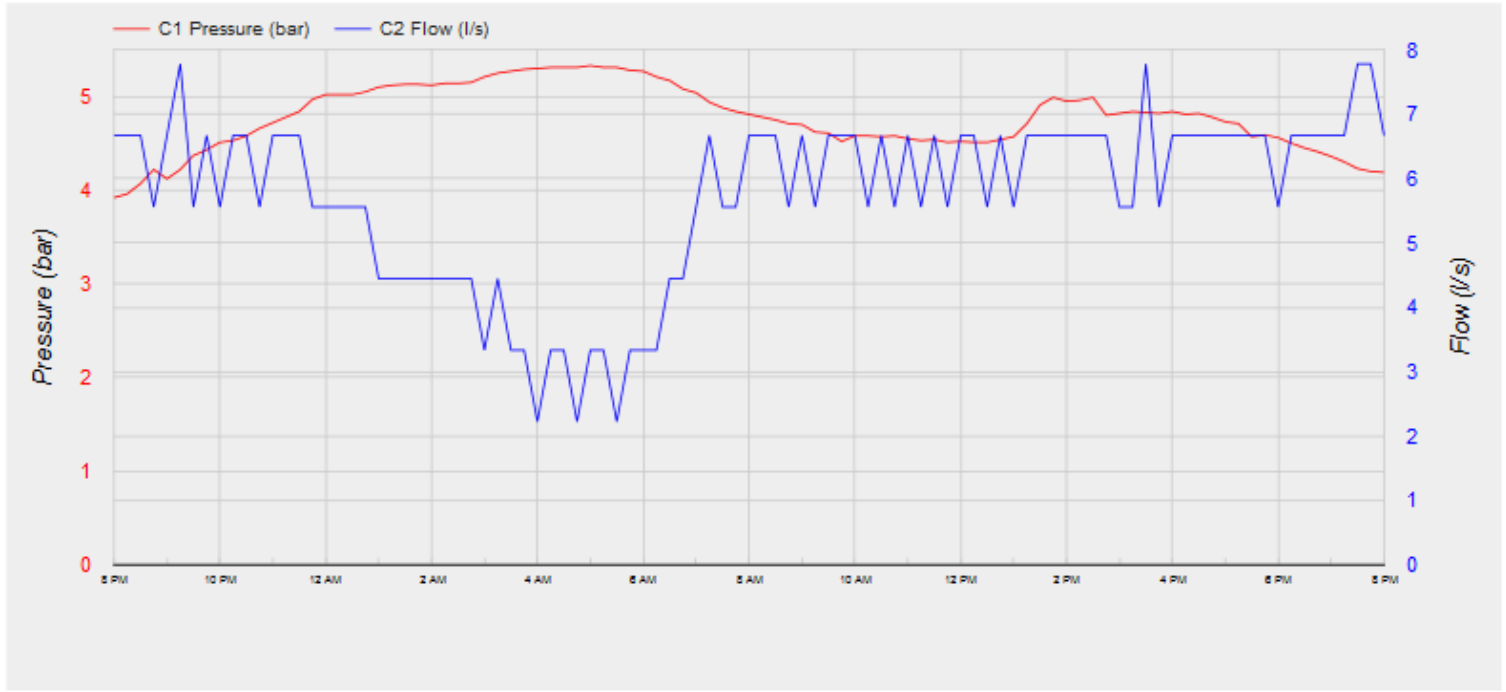

Data Statistics

\begin{tabular}{lllll}
\hline Channel & Max. & Min. & Volume (Average) & Meter Read (30Jun2016 20:00) \\
\hline C1 Pressure (bar) & 5.33 & 3.92 & $(4.775)$ & - \\
C2 Flow (l/s) & 7.778 & 2.222 & $492 \mathrm{~m}^{3}(5.694)$ & $18236 \mathrm{~m}^{3}$
\end{tabular}

Fig.3:- - 1-st online monitoring zone with GPRS logger

Bregu i Diellit|4 77317, Hidropresa Phone: 37745987114 Site ID: loger 4 From: 29Jun2016 15:00 To: 30 Jun2016 15:00 (5 Mins)

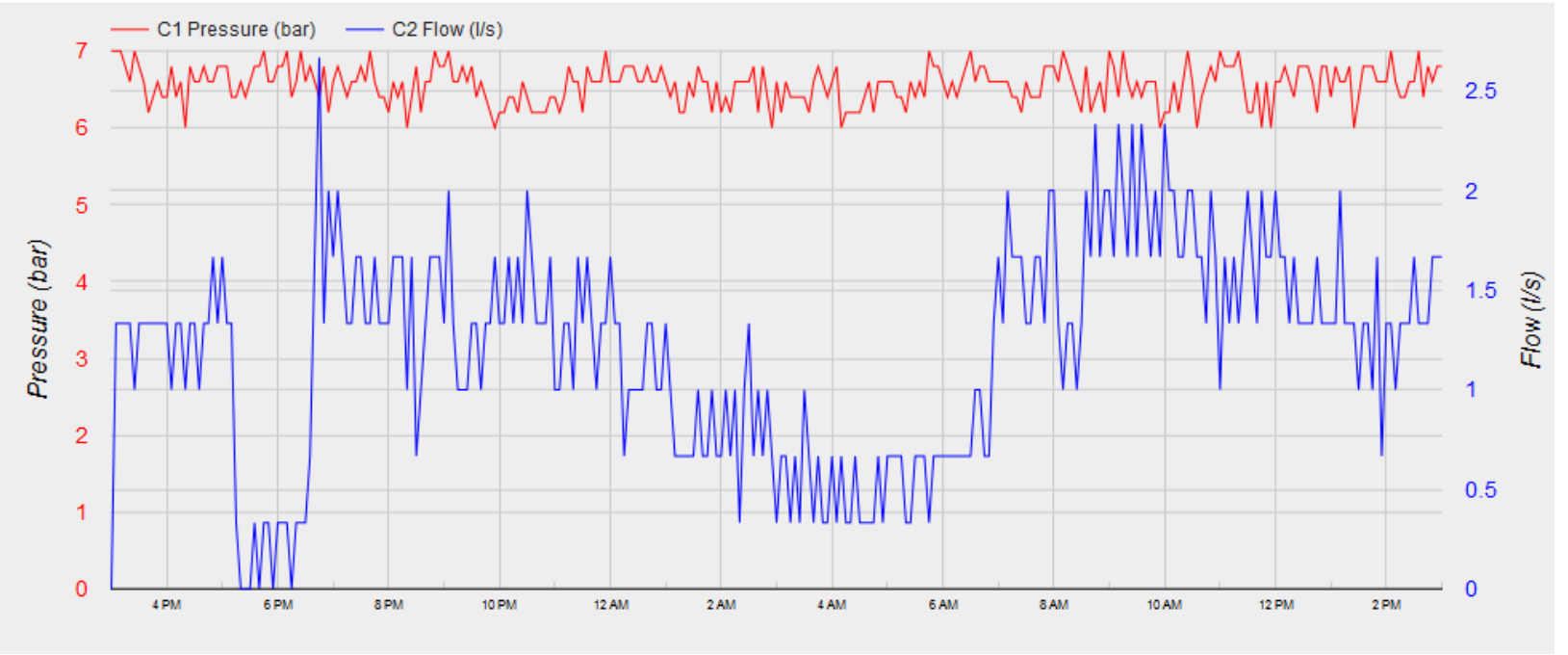

Fig.4:- - 2-nd online monitoring zone. 


\section{Results from the measures and activities on site :-}

As a part of leakage control, and water loss reduction are also surveys and active controls on site. The measures that we undertake on the company for these monitoring's, were made by "Flexim" ultrasonic flow meter, palmer and "SebaKMT" devices including pressure loggers, ground microphones, "SebaKMT" correlators etc. In Lipjan DMA where all the devices were used on site and compared with online monitoring we achieved the results, and the main indicator that is evaluated is the Minimum Night Flow (MNF) as an indicator that shows the real result, results are presented

below

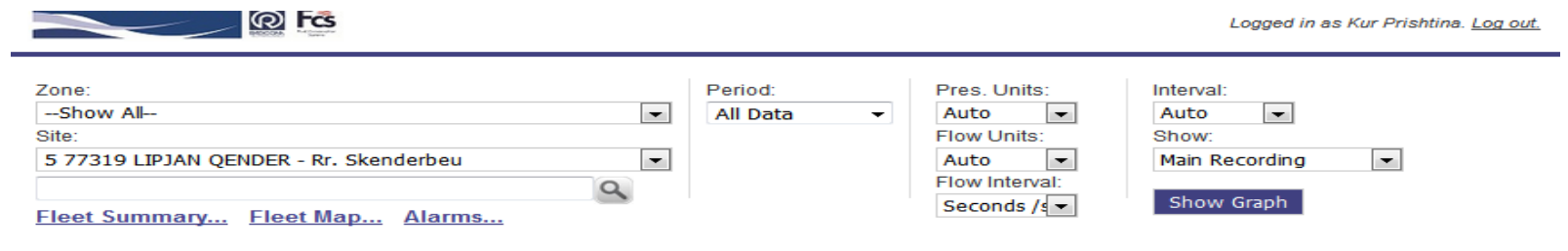

; 77319 LIPJAN QENDER - Rr. Skenderbeu Phone: 37745941629 Site ID: Logger 5 From: 22Oct2015 13:00 To: 03Apr2016 08:00 (1 Hour)

$$
\text { C1 Pressure (bar) C2 Flow (Vs) }
$$

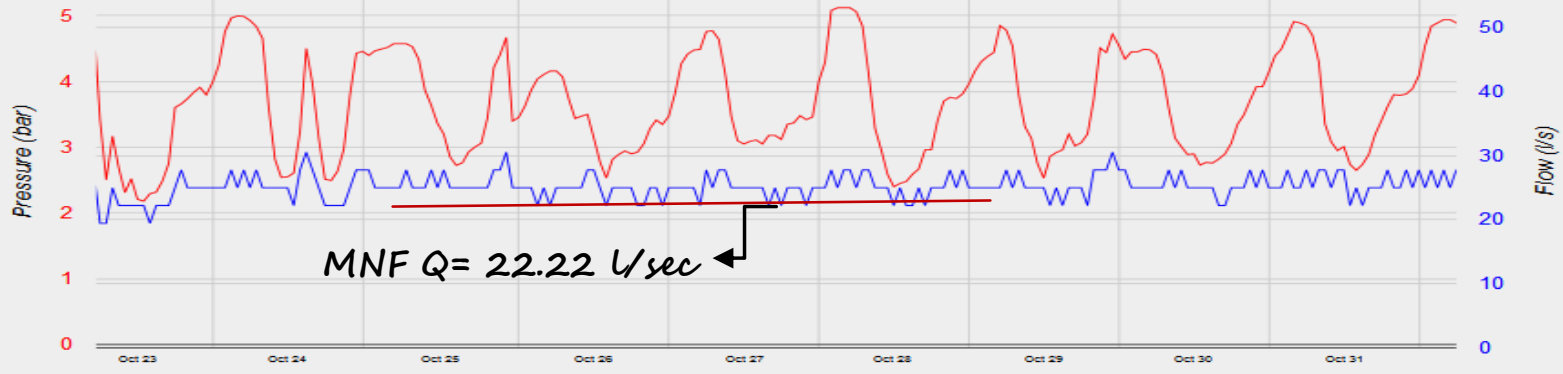

Jata Statistics

$\begin{array}{lllll}\text { Ehannel } & \text { Max. } & \text { Min. } & \text { Volume (Average) } & \text { Meter Read (03Apr2016 08:00) } \\ \text { 21 Pressure (bar) } & 5.63 & -0.05 & (3.864) & - \\ \text { 22 Flow (1/s) } & 58.333 & 0 & 313101 \mathrm{~m}^{3}(22.125) & 313171.031 \mathrm{~m}^{3}\end{array}$

Fig.5:- Charts from monitoring online MNF in during measurements.

\begin{tabular}{|c|c|c|c|c|c|c|c|}
\hline \multicolumn{2}{|l|}{ Zone: } & \multicolumn{2}{|l|}{ Period: } & \multicolumn{2}{|c|}{ Pres. Units: } & \multicolumn{2}{|l|}{ Interval: } \\
\hline --Show All-- & - & \multirow{3}{*}{$\begin{array}{l}\text { Custom } \\
\text { start } \\
03 / 05 / 2016 \\
00: 00\end{array}$} & 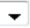 & Auto & - & Auto & \\
\hline Site: & & & & \multicolumn{2}{|c|}{ Flow Units: } & \multicolumn{2}{|l|}{ Show: } \\
\hline \multirow{2}{*}{577319 LIPJAN QENDER - Rr. Skenderbeu } & - & & & Auto & - & Main Recording & - \\
\hline & a & \multirow{2}{*}{$\begin{array}{l}\text { end } \\
07 / 05 / 2016\end{array}$} & & \multicolumn{2}{|c|}{ Flow Interval: } & & \\
\hline Fleet Summary... Fleet Map... Alarms... & & & & Secor & - & Show Graph & \\
\hline
\end{tabular}

577319 LIPJAN QENDER - Rr. Skenderbeu Phone: 37745941629 Site ID: Logger 5 From: 03May2016 00:00 To: 07May2016 00:00 (1 Hour)

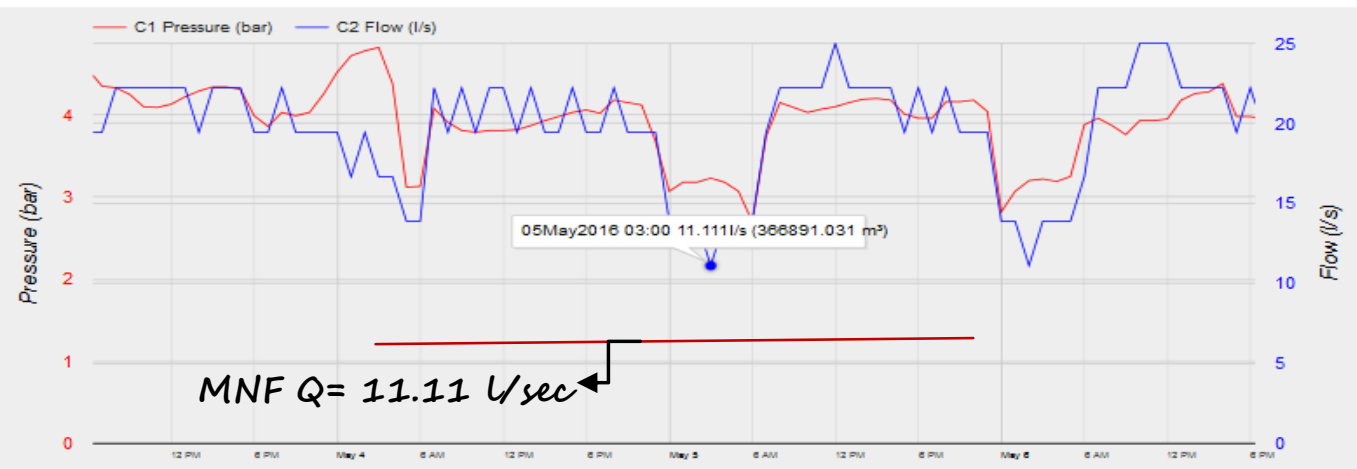


Fig.6:- Charts from monitoring online MNF -results on real loss reduction.

The results were evaluated in DMA pilot zone in Lipjan, were also a trained teams found more than 6 leaks, than after all these leaks were repaired and stopped, also based on the results taken on this particular DMA zone the Utility Unit in Lipjan is doing pressure management control. After all these measures; a hydraulic model was generated with Epanet software, and also an IWA standard water balance with WB Easy Calc. (software supported by IWA).

\begin{tabular}{|c|c|}
\hline \multicolumn{2}{|c|}{ RESULTS FROM THE MEASUREMNTS' TAKEN ON DMA } \\
\hline Q daily inflow - Oct. 2015 & Q daily inflow- May 2016 \\
\hline $\mathrm{Q}=30 \mathrm{l} / \mathrm{sec}$ & $\mathrm{Q}=25 \mathrm{l} / \mathrm{sec}$ \\
\hline Q $\min (\mathrm{MNF})$ - Oct. 2015 & Q $\min ($ MNF ) - May 2016 \\
\hline $\mathrm{Q}=22 \mathrm{l} / \mathrm{sec}$ & $\mathrm{Q}=11.11 \mathrm{l} / \mathrm{sec}$ \\
\hline \multicolumn{2}{|c|}{ REAL LOSS REDUCTION - SAVINGS } \\
\hline \multicolumn{2}{|c|}{ REDUCTION OF Q ( MNF ) => 6138 m³/Month } \\
\hline \multicolumn{2}{|c|}{ REDUCTION OF Q $(\max ) \Rightarrow 5580 \mathrm{~m}^{3} /$ Month } \\
\hline \multicolumn{2}{|c|}{ REDUCTION OF Q $($ total $)=>11,718 \mathrm{~m}^{3} /$ Month } \\
\hline \multicolumn{2}{|c|}{ SAVINGS IN EURO = 71,352.40 Euro / Year } \\
\hline
\end{tabular}

\section{Conclusion}

The paper includes the methodology or the techniques to be followed for reducing water losses in distribution networks by creating the county measuring areas, methods how to build them.

Equipment to be placed and equipment for detection of invisible losses reaching to the result and give solution to problems of water losses that have high level in our country and comes from many factors not excluding commercial losses which make up a huge percentage of the total loss.

\section{Acknowledgements:-}

I would like to express my deepest gratitude to department of water loss detection at RWC, Pristina; for their tireless work on site also Operational Unit in Lipjan. This would have not been possible without their professional work on this field.

\section{References:-}

1. (C) European Union, 2015 EU Reference document Good Practices on Leakage Management WFD CIS WG PoM -Main Report, ISBN 978-92-79-45069-3, doi: 10.2779/102151

2. Farley, M., Trown, S. (2003). Losses in water distribution networks: A practitioner's guide to assessment, monitoring and control (p. 10). London: IWA. 